\title{
Jogos digitais educacionais como instrumento didático no processo de ensino-aprendizagem das operações básicas de matemática
}

\author{
Bruna Camargo da Silva, Patrick Pedreira Silva, Larissa Pavarini da Luz, Elvio \\ Gilberto Silva, Henrique Pachioni Martins ${ }^{1}$ \\ ${ }^{1}$ Centro de Ciências Exatas e Sociais Aplicadas - Universidade Sagrado Coração (USC) \\ Bauru - SP - Brazil \\ \{brunacams, larissapavarinidaluz\}@gmail.com, \{patrick.silva, egsilva, \\ henrique.martins\} @usc.br
}

\begin{abstract}
Resumo. $O$ déficit de aprendizado da matemática é um dos grandes desafios que as escolas têm enfrentado. Neste contexto, os jogos digitais, mostram-se excelentes alternativas a fim de potencializar a abstração de conhecimento de uma geração que nasceu em meio à tecnologia. Este trabalho visou desenvolver um jogo digital, para crianças, entre 7 a 9 anos, que as permitisse exercitar os conceitos de adição e subtração. O software, que foi aplicado em uma escola, apresentou resultados positivos e foi bem recebido pelas crianças que se sentiram motivadas em calcular.
\end{abstract}

\section{Introdução}

Segundo Selva e Camargo (2009), o processo de ensino-aprendizagem da matemática é constantemente questionado a fim de se alcançar melhorias, principalmente devido ao temor que os alunos sentem em relação a esta disciplina, o que acaba por dificultá-lo. Afirmam ainda que por tradição a matemática é tida como uma ciência rigorosa, formal e abstrata, concepções que dificultam esse processo e levam a práticas pedagógicas que nem sempre permitem a compreensão, e consequentemente não permitem a construção do conhecimento.

O relatório "De olho nas metas" de 2012, quinto relatório de monitoramento das cinco metas de "Todos Pela Educação", que prevê em sua meta número três que $70 \%$ ou mais dos alunos terão aprendido o que é essencial para a sua série até 2022 , revela que no final da primeira etapa do Ensino Fundamental apenas 36\% dos alunos atingiram níveis essenciais de aprendizado em matemática [Todos pela Educação 2012]. Esse dado aponta o baixo desempenho em matemática logo nas séries iniciais, que tende piorar no final da segunda etapa do Ensino Fundamental, onde, ainda de acordo com o "Todos Pela Educação" (2012a), cai para 16,9\% e chega a apenas 10\% no fim do Ensino Médio.

A Prova ABC (Avaliação Brasileira do Final de Ciclo de Alfabetização) que verifica a qualidade de alfabetização das crianças que concluíram o $3^{\circ}$ ano do Ensino Fundamental mostrou em 2011, segundo "Todos Pela Educação" (2012b), que apenas $42,83 \%$ aprenderam aquilo que se é esperado em matemática, ou seja, cerca de $57,17 \%$ 
não conseguem resolver questões simples como adição e subtração de números, que são habilidades avaliadas pela prova.

A partir dessa informação, percebe-se que o baixo desempenho apresentado no Final do Ensino Fundamental I e II, e do Ensino Médio já começa a ter indícios nos primeiros anos da vida escolar, o que leva a necessidade de incentivar o aprendizado da matemática desde o período de alfabetização e buscar novos métodos de ensino que venham melhorar a relação entre os alunos, os professores e o conhecimento, de forma que os alunos alcancem desempenho satisfatório e não acumulem essa dificuldade para os anos seguintes. De acordo com Freire (2011), ensinar não é apenas transferir conhecimento, mas criar formas para que o aluno possa produzi-lo ou construí-lo.

Suaiden e Oliveira (2006) afirmam que crianças e jovens estão desmotivados em aprender aquilo que é imposto pela escola, ainda mais da forma como ela faz isso, seguindo parâmetros educacionais que são regidos por princípios da sociedade anterior, fora do contexto em que estão inseridas as gerações atuais que nasceram em meio à revolução tecnológica atual; e Jucá (2006) diz que as novas tecnologias mostram que quando são utilizadas adequadamente auxiliam no processo da construção do conhecimento.

Tomando as citações de Juca (2006) e Suaiden e Oliveira (2006) como base, pode-se afirmar que o uso adequado da tecnologia é capaz de ser uma ferramenta auxiliar no ensino-aprendizagem da matemática, desmistificando a ideia de que ela seja uma ciência complicada. Dentro disto estão os jogos educacionais digitais que de acordo com Lima, Silva e Silva (2009) se mostram excelentes ferramentas pedagógicas capazes de potencializar o ensino-aprendizagem.

Este trabalho tem como objetivo o desenvolvimento de um jogo digital que permitia ao aluno, na faixa etária de 7 a 9 anos, exercitar cálculos que envolvam as operações adição e subtração, todas dentro do contexto do jogo, utilizando-se de recursos que façam com que o aluno sinta-se motivado em realizá-las, através de telas atrativas, cores, sons e desafios.

\section{Jogos digitais como instrumento didático}

Os autores Camargo e Neves (2005) dizem que por estarem inseridos na vida do indivíduo, desde o seu nascimento, no contexto social e no seu comportamento, jogos e brincadeiras são fundamentais para o desenvolvimento da criança, que assimila e recria experiências socioculturais dos adultos através deles. Tarouco et al (2004) afirma que ao divertir enquanto motivam, os jogos possuem a capacidade de facilitar o aprendizado, aumentar a retenção do que foi ensinado e exercitar as funções mentais e intelectuais do jogador, podendo ser ferramentas instrucionais eficientes.

Segundo Jordão (2009) existe diferenças na forma em que nativos digitais, aqueles que nasceram em meio ao desenvolvimento tecnológico, agem e aprendem, não mais adiantando usar as mesmas estratégias educacionais que foram utilizadas pelos professores das gerações passadas. É preciso que haja uma adaptação à agilidade de pensamento e à velocidade do acesso à informação que os alunos possuem atualmente.

Levando-se em consideração que as gerações de crianças atuais são formadas por nativos digitais e possuem uma forma diferenciada de se aprender através da tecnologia, 
a união entre os jogos e a tecnologia, dando origem aos jogos digitais, mostra-se uma excelente alternativa de ensino-aprendizagem.

\section{Trabalhos Correlatos}

Um exemplo de jogo digital matemático brasileiro é o GeoplanoPEC desenvolvido pelo Laboratório de Tecnologias para Ensino Virtual e Estatística (LabTEVE) da Universidade Federal da Paraíba e que faz parte de um projeto financiado pela Financiadora de Estudos e Projetos (Finep). O jogo trabalha conceitos de geometria plana abordados nos $5^{\circ}$ e $6^{\circ}$ anos do Ensino Fundamental, baseado no tabuleiro do Geoespaço (LABTEVE, 2012).

Outro projeto bem sucedido é o Math City que se trata de um trabalho colaborativo que integrou pais, professores e alunos para a construção de conceitos matemáticos. O jogo foi aplicado a alunos considerados inaptos ou aptos com restrição para entrar no $6^{\mathrm{o}}$ ano do Ensino Fundamental. A investigação mostra que percentual de alunos reprovados caiu consideravelmente de 2004 a 2007, sendo este último ano aquele em que foi implementado o projeto (deve-se levar em consideração que os alunos tiveram o mesmo professor de matemática durante os quatro anos). Math City é um exemplo brasileiro de sucesso na aplicação de jogos digitais como instrumento de ensinoaprendizagem de matemática (NASCIMENTO; REIS, 2008).

\section{Desenvolvendo um jogo educativo matemático}

Toda a parte gráfica do software foi construída através da ferramenta Inkscape e as ações programadas na linguagem Action Script 3.0 utilizando como ferramenta o Adobe Flash Professional CC.

A escolha dessa ferramenta deu-se pelo fato do Adobe Flash Professional ser bastante intuitivo e possuir uma linguagem de programação simples, mas ao mesmo tempo oferecer os recursos necessários para que essa aplicação fosse desenvolvida de acordo com aquilo que se foi proposto inicialmente. O jogo também poderá ser executado através de um browser, o que além de torná-lo capaz de funcionar em vários Sistemas Operacionais, também pode facilmente ser disponibilizado na internet para ser utilizado online de qualquer lugar. Na Figura 1 é possível ver a tela inicial do jogo desenvolvido.

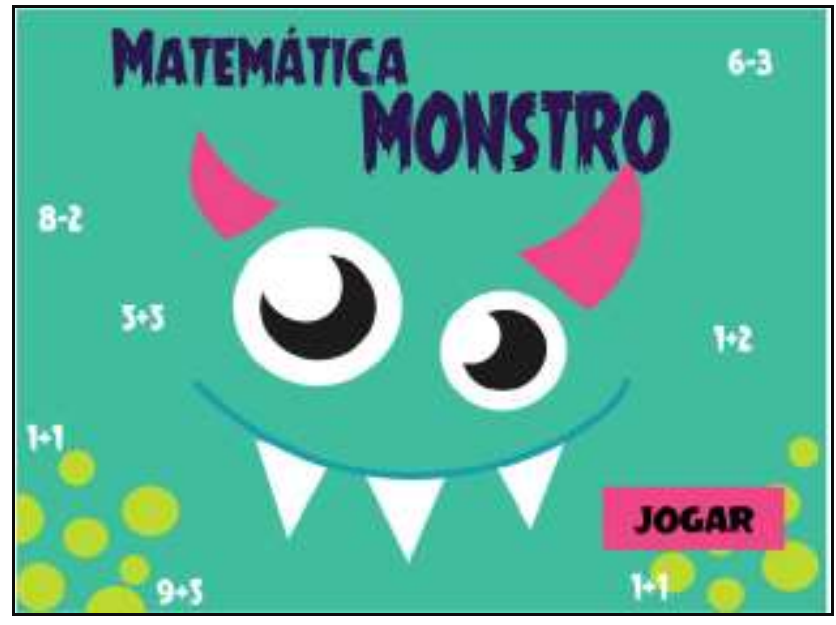


Figura 1 - Tela Inicial.

\section{Fonte: Elaborado pela autora (2013).}

O conceito do jogo, que foi chamado de "Matemática Monstro", tem como base o tradicional Jogo de Memória, onde existem cartas com figuras em um dos lados, que se repetem em duas cartas diferentes. Essas cartas ficam todas embaralhadas e com as suas faces estampadas voltadas para baixo. Os jogadores na sua vez possuem o direito de virar duas cartas na tentativa de encontrar o par. Quando o par é descoberto, o jogador o recolhe e tem o direito de jogar novamente. Quando ele erra, as cartas são viradas novamente e é a vez do próximo jogador.

A diferença do jogo desenvolvido, para o jogo tradicional, além de ser um jogo digital, é que no lugar de figuras iguais, os pares de cartas são operações matemáticas com seus respectivos resultados (Figura 2).

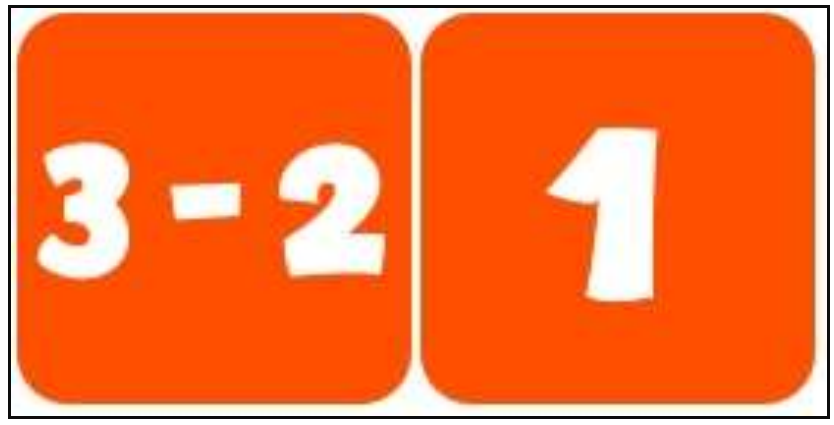

Figura 2 - Exemplo de par de cartas de "Subtrair" Fonte: Elaborado pela autora (2013).

Conforme o jogador encontra os pares, estes vão desaparecendo até que não reste mais nenhuma carta. Quando isso acontece, o jogador passa de fase. A diferença entre uma fase e outra é o nível de dificuldade das operações.

Os monstrinhos estampados nas fases têm como intuito chamar a atenção da criança.

\section{Avaliação do Software}

A fim de analisar a interação das crianças com o software, o mesmo foi aplicado em uma escola municipal em Botucatu - SP. O trabalho foi realizado em uma turma do $4^{\circ}$ ano do Ensino Fundamental, com alunos de 9 anos, no período da manhã e teve duração de uma hora e meia. A aplicação contou com a participação de vinte alunos, que foram divididos em grupos de cinco. Cada um desses grupos era enviado por sua professora até o local da aplicação. Quando todos os alunos do grupo terminavam a atividade, este voltava para a sua sala de aula e novo grupo era enviado para nova realização. O processo se repetiu até que todos os vinte alunos tivessem participado.

A escola não possui laboratório de informática, portanto as atividades foram realizadas com um notebook, rodando o Sistema Operacional Windows Seven, com o processador Intel @ Core TM $15-24102.30 \mathrm{GHz}$ e 4GB de RAM, e um mouse externo.

Primeiramente, houve uma rápida explicação do funcionamento do jogo e logo em seguida, os alunos ficaram livres para jogar, revezando-se no notebook. Cada um 
deles pôde jogar duas fases, antes de passar a vez para o próximo. A escolha da ordem dos alunos que utilizaram o software partiu deles mesmos.

Após o contato das crianças com o software, eles responderam um questionário simples encontrado no Anexo A deste trabalho.

\subsection{Aplicação da ferramenta com crianças}

As crianças ficaram muito empolgadas diante da possibilidade de jogar no computador, mesmo sabendo tratar-se de um jogo educativo. Não houve qualquer resistência por parte de nenhuma delas, todas quiseram participar sem exceções.

Não houve dificuldades na utilização do mouse para fazer uso do software. Aqueles que não estavam acostumados com o uso de computadores foram auxiliados pelos próprios colegas e rapidamente se familiarizaram com o funcionamento do jogo e com o uso do mouse, confirmando a facilidade que eles possuem em lidar com a tecnologia, exatamente por fazer parte de uma geração que tem crescido em meio ao desenvolvimento tecnológico, conforme já discutido anteriormente neste trabalho.

A maioria já estava habituada com o uso do computador e houve alunos que manifestaram o interesse de obter o jogo para poder jogar mais em suas casas, o que nos permite observar o interesse da criança nesse tipo de atividade. Mesmo sabendo que cada um poderia jogar apenas duas fases, muitos pediam para jogar novamente.

Aqueles que não estavam jogando, se colocaram ao redor do colega no notebook, para observar e até mesmo ajudar, fazendo daquele, um momento de trabalho em equipe. Eles vibravam com cada acerto, mesmo que fosse o do outro colega.

Foi visível a cooperação entre eles e a facilidade com que se adaptaram a necessidade de revezar um único notebook entre todos, motivados pelo fato de poderem jogar um pouco.

Quando questionados sobre a aplicação, todos disseram ter gostado muito, afirmaram não terem tido dificuldades em entender como o software funcionava, que foi fácil familiarizar-se com ele e que era "bonito", ou seja, possuía uma interface agradável.

Manifestaram o interesse de que os professores utilizassem aplicações semelhantes durante as aulas de matemática e pediram para que outros jogos fossem testados com eles mais vezes.

\subsection{Resultados da observação e questionários}

De acordo com o objetivo deste trabalho, os alunos, durante a aplicação do software, foram observados e questionados, tanto de maneira informal, quanto através de um questionário, a fim de avaliar o jogo quanto a sua usabilidade.

No total, como já dito anteriormente, participaram desse processo 20 alunos com idade média de 9 anos. Os gráficos apresentados nesse tópico representam os resultados obtidos através do questionário. 
O primeiro gráfico (Figura 3) refere-se à opinião dos alunos quanto ao jogo, se eles gostaram e se divertiram jogando. Dos 20 alunos, todos afirmaram ter gostado muito. Pode-se observar a satisfação das crianças enquanto jogavam, além disso, elas expressaram verbalmente o quanto desejavam poder jogar mais tempo.

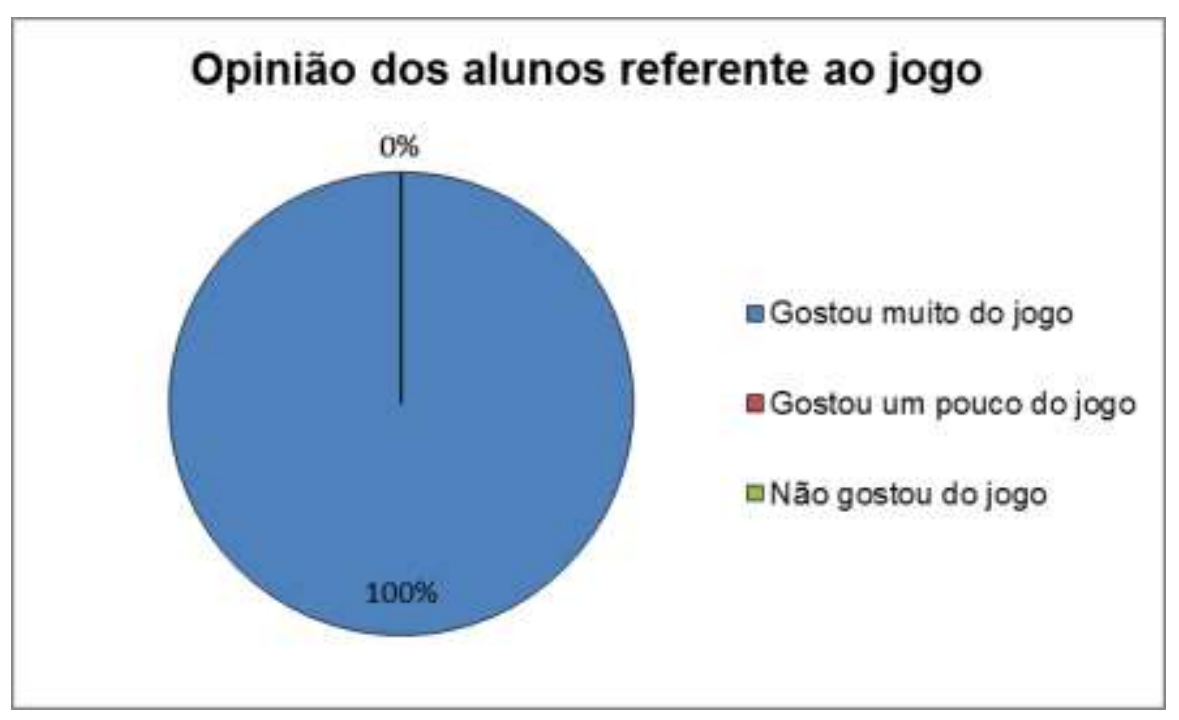

Figura 3 - Opinião dos alunos referente ao jogo.

Fonte: Elaborado pela autora (2013).

O fato da base do jogo desenvolvido ser o tradicional Jogo de Memória, muito contribuiu para que as crianças entendessem a sua mecânica. Apesar de no software, o par de cartas não se tratar de figuras iguais como no jogo popular, mas de uma operação e o seu resultado, em nenhum momento eles tiveram dificuldade de assimilar essa mudança e rapidamente aprenderam como jogar.

A Figura 4 representa o entendimento dos alunos quanto à mecânica do jogo. Todos os alunos afirmaram ter entendido como de jogava.

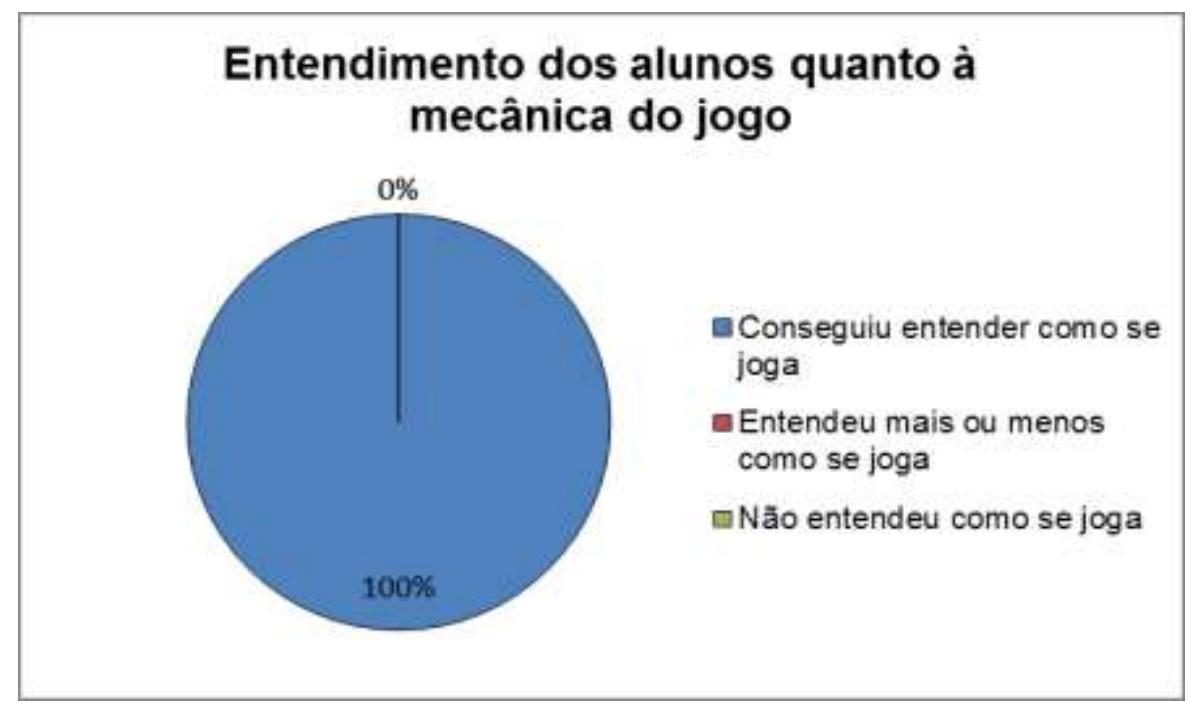

Figura 4 - Entendimento dos alunos quanto à mecânica do jogo Fonte: Elaborado pela autora (2013). 
Durante a aplicação, alguns alunos nunca haviam brincado de Jogo de Memória antes e acabaram aprendendo através da rápida explicação inicial e observando as outras crianças enquanto jogavam, sem terem apresentado dificuldades na sua vez por conta disso.

As crianças não apenas aprenderam com facilidade como jogar, como igualmente manipularam o jogo com a mesma facilidade. Os botões do software foram colocados em locais visíveis e especificam de forma direta a sua função. Após terem sido ensinadas apenas uma vez, pode-se observar que elas sabiam iniciar o jogo, escolher a operação que queriam jogar, voltar ao menu e reiniciar a fase. Elas mesmas colocavam o jogo novamente no estado inicial, quando sua vez acabava, para que a próxima criança pudesse jogar. Todas elas afirmaram que foi fácil mexer no jogo, como mostra a Figura 5 .

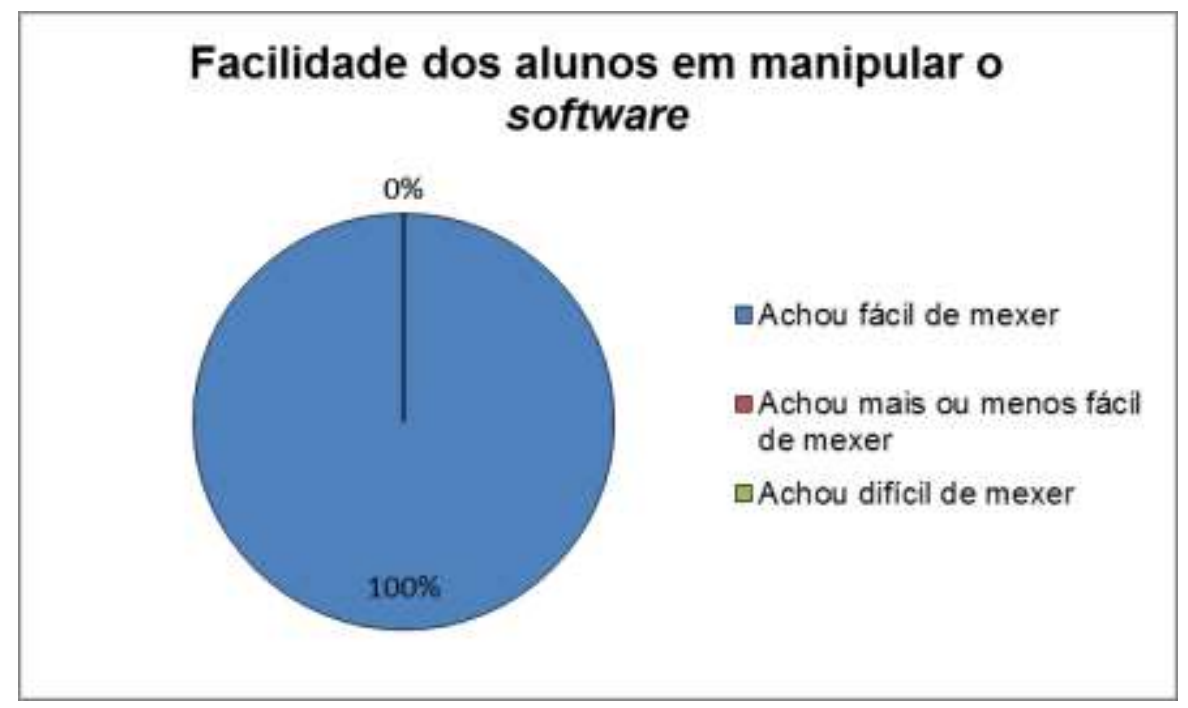

Figura 5 - Facilidade dos alunos em manipular o software.

Fonte: Elaborado pela autora (2013).

Foi interessante observar a forma como os alunos ajudavam uns aos outros com os cálculos. Eles calculavam as operações em voz alta, a fim de descobrirem juntos o resultado e encontrarem a carta certa. Visivelmente eles se sentiram estimulados em calcular.

Os alunos também foram questionados quanto à frequência em que seus professores utilizavam jogos de computador durante as aulas. A Figura 6 mostra que $85 \%$ deles responderam que isso nunca foi feito. 


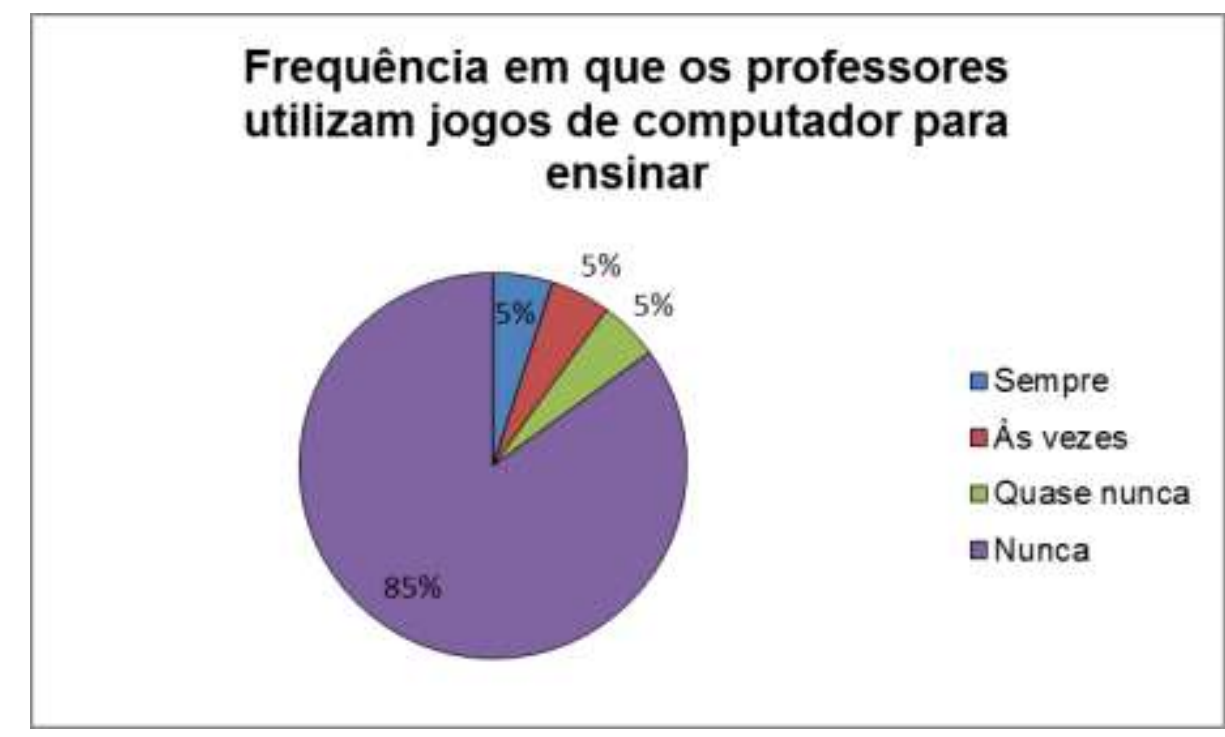

Figura 6 - Frequência em que os professores utilizam jogos de computador para ensinar.

Fonte: Elaborado pela autora (2013).

Também foi lhes perguntado se gostariam de aprender matemática usando jogos, se teriam maior interesse na matéria dessa maneira, e a resposta foi unânime. Todos responderem de forma positiva (Figura 7).

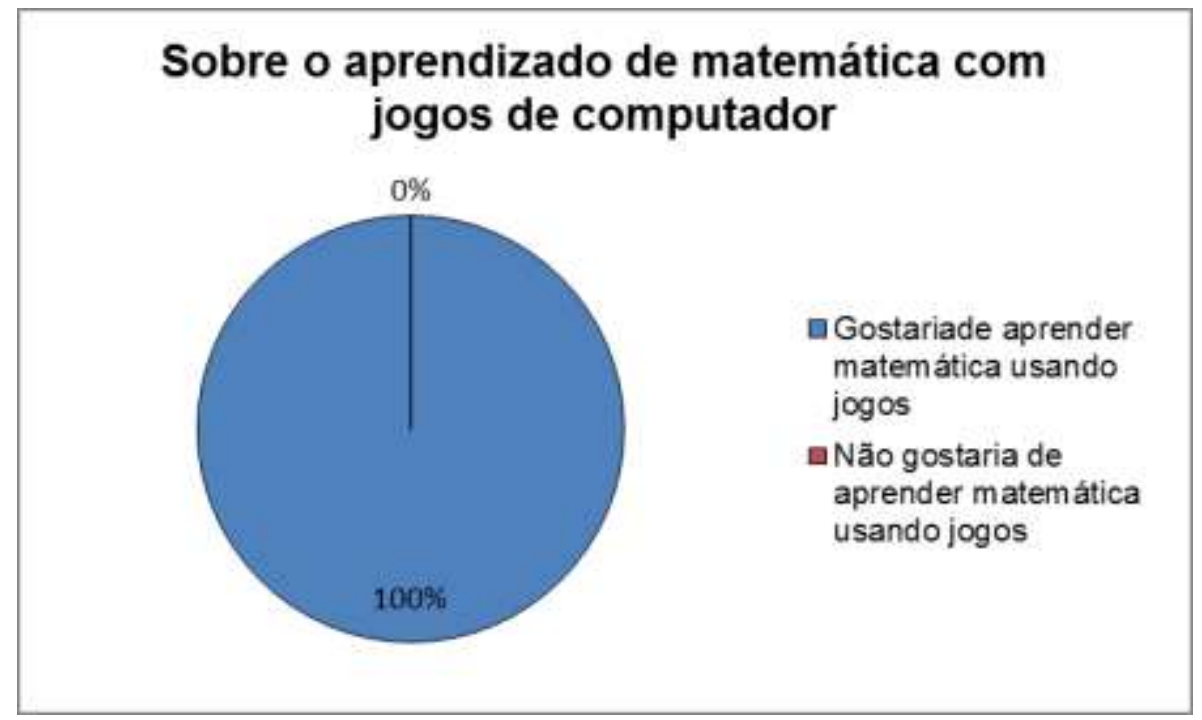

Figura 7 - Sobre o aprendizado de matemática com jogos de computador Fonte: Elaborado pela autora (2013).

\section{Considerações finais}

Os jogos de computador são uma excelente ferramenta para auxiliar no processo de ensino-aprendizagem. A criança sente-se motivada e mais disposta a aprender, conforme visto neste trabalho. 
Nos dias atuais, onde a matemática é muitas vezes encarada como vilã, levandose em consideração os problemas que a escola tem enfrentado em relação a ela, baseando-se nos dados obtidos do "Todos Pela Educação", a criação e o uso dos jogos focados nessa disciplina deve ser visto como algo natural na evolução dos métodos educacionais. Principalmente, tendo a meta de que até 2012, 70\% dos alunos terão aprendido o que é adequado ao seu ano, quando atualmente essa porcentagem fica em torno de $10 \%$ dos alunos que terminam o Ensino Médio.

Através desse trabalho, pode-se verificar que é possível a construção de um jogo simples, multiplataforma, que atenda as necessidades específicas da educação, quando bem planejado.

Mesmo com ferramentas simples, foi possível criar um jogo que possuísse o básico de elementos de usabilidade como satisfação do usuário, facilidade de aprender, facilidade de relembrar e a eficiência em cumprir o objetivo para o qual ele foi proposto.

Como trabalhos futuros, sugere-se a ampliação do jogo, acrescentando-se novas fases e os tipos de operação que não foram trabalhados (multiplicação e divisão). É possível também o trabalho com frações, sendo uma carta uma figura e seu respectivo par a representação numérica em forma de fração daquela figura.

Quanto à interface do jogo, é possível a criação de animações para os objetos que estão na tela, a fim de torná-los ainda mais atrativos.

Levando-se em conta o trabalho em equipe apresentado pelos alunos durante a aplicação, pode-se também considerar a possibilidade de transformá-lo em um jogo multiplayer, tanto para um trabalho em conjunto, quanto para uma disputa entre dois jogadores.

\section{Referências}

CAMARGO, H. M. M; NEVES, R. L. R. Jogos e brincadeiras: a sistematização do trabalho pedagógico na disciplina de Didática e Prática de Ensino I, na Escola Municipal Lenival Correia Ferreira no $2^{\circ}$ semestre, 2005. Revista Digital Efdeportes, Buenos Aires, año 12, n. 108, mayo 2007. Disponível em: < http://www.efdeportes.com/efd108/jogos-e-brincadeiras-a-sistematizacao-dotrabalho-pedagogico.htm > Acesso em: 04 de maio de 2013.

FREIRE, P. Pedagogia da autonomia: saberes necessários à prática educativa. 43. ed. São Paulo: Paz e Terra, 2011. 143 p.

JORDÃO, T. C. Formação de educadores: A formação do professor para a educação em um mundo digital. Salto Para O Futuro, [s. L.], n., p.9-17, nov. 2009. Bimestral. Disponível em: $\quad<$ http://www.tvbrasil.org.br/fotos/salto/series/17432019TecnologiasDigitaisEdu.pdf $>$. Acesso em: 12 maio 2013.

JUCÁ, S. C. S. A relevância dos softwares educativos na educação profissional. Ciência e Cognição, Rio de Janeiro, v.8, ago. 2006. Disponível em: $<$ http://www.cienciasecognicao.org/revista/index.php/cec/article/view/571/359>. Acesso em: 05 mar. 2012

LIMA, M. C. F; SILVA, V. V. S; SILVA, M. E. L. Jogos educativos no âmbito educacional: um estudo sobre o uso dos jogos no projeto MAIS da rede municipal de 
Recife.

Disponível

em: $<$ http://www.ufpe.br/ce/images/Graduacao_pedagogia/pdf/2009.2/jogos educativos no ambito educacional um estudo sobre o uso.pdf $>$. Acesso em: 15 nov. 2013.

NASCIMENTO, V. A; REIS, F. C. S. O desenvolvimento do jogo Math City em um contexto colaborativo: professores e alunos para a construção de conhecimentos matemáticos. Disponível em: <http://www.de.ufpb.br/ labteve/projetos/jogos.html>. Acesso em: 19 maio 2013.

SELVA, K. R.; CAMARGO, M. O jogo matemático como recurso para a construção do conhecimento. In: X ENCONTRO GAÚCHO DE EDUCAÇÃO MATEMÁTICA, 2009, Ijuí. Disponível em: $<$ http://www.projetos.unijui.edu.br/matematica/cd_egem/fscommand/CC/CC_4.pdf $>$ Acesso em: 06 mar. 2013

SUAIDEN, E. J; OLIVEIRA, C. L. A ciência da informação e um novo modelo educacional: escola digital integrada. In: MIRANDA, Antônio; SIMEÃO, Elmira. (Org.). Alfabetização digital e acesso ao conhecimento. Brasília: Universidade de Brasília, Departamento de Ciência da Informação e Documentação, 2006. p. 95-108.

TAROUCO, L. M. R et al. Jogos educacionais. Revista Novas Tecnologias na Educação, Rio Grande do Sul, v.2, n. 1, mar. 2004. Disponível em: < http://www.virtual.ufc.br/cursouca/modulo_3/Jogos_Educacionais.pdf Acesso em: 04 maio 2013.

TODOS PELA EDUCAÇÃO. De olho nas metas: quinto relatório de monitoramento das 5 metas do "Todos Pela Educação". 2012a. Disponível em: < http://www.todospelaeducacao.org.br/biblioteca/1476/de-olho-nas-metas-2012> Acesso em: 05 mar. 2013

TODOS PELA EDUCAÇÃO. Prova ABC: Resultados da Avaliação de Aprendizagem de Leitura e Matemática. 2012b. Disponível em: $<$ http://www2.camara.leg.br/atividade-legislativa/comissoes/comissoestemporarias/especiais/54a-legislatura/pl-8035-10-plano-nacional-deeducacao/arquivos/resultado-prova-abc>. Acesso em: 03 maio 2013. 